\title{
Effects of Forming Gas Anneal on Ultrathin InGaAs Nanowire Metal-Oxide-Semiconductor Field-Effect Transistors
}

\section{Citation}

Si, Mengwei, Jiangjiang J. Gu, Xinwei Wang, Jiayi Shao, Xuefei Li, Michael J. Manfra, Roy Gerald Gordon, and Peide D. Ye. 2013. Effects of forming gas anneal on ultrathin InGaAs nanowire metal-oxide-semiconductor field-effect transistors. Applied Physics Letters 102(9): 093505.

\section{Published Version}

doi:10.1063/1.4794846

\section{Permanent link}

http://nrs.harvard.edu/urn-3:HUL.InstRepos:10384785

\section{Terms of Use}

This article was downloaded from Harvard University's DASH repository, and is made available under the terms and conditions applicable to Open Access Policy Articles, as set forth at http:// nrs.harvard.edu/urn-3:HUL.InstRepos:dash.current.terms-of-use\#OAP

\section{Share Your Story}

The Harvard community has made this article openly available.

Please share how this access benefits you. Submit a story.

\section{Accessibility}




\section{Effects of Forming Gas Anneal on Ultrathin InGaAs Nanowire Metal-Oxide- Semiconductor Field-Effect Transistors}

Mengwei $\mathrm{Si}^{1)}$, Jiangjiang J. Gu ${ }^{1)}$, Xinwei Wang ${ }^{2)}{ }^{4)}$, Jiayi Shao ${ }^{3)}$, Xuefei Li $^{1)}$, Michael J. Manfra 1) 3) 5), Roy G. Gordon ${ }^{2)}$, and Peide D. Ye ${ }^{1) \text { a) }}$

1) School of Electrical and Computer Engineering and Birck Nanotechnology Center, Purdue University, West Lafayette, IN 47907, U.S.A.

2) Department of Chemistry and Chemical Biology, Harvard University, Cambridge, MA 02138, U.S.A.

3) Department of Physics, Purdue University, West Lafayette, IN 47907, U.S.A.

4) School of Advanced Materials, Peking University Shenzhen Graduate School, Shenzhen 518055, China

5) School of Materials Engineering, Purdue University, West Lafayette, IN 47907, U.S.A.

InGaAs gate-all-around (GAA) metal-oxide-semiconductor field-effect transistors (MOSFETs) with $6 \mathrm{~nm}$ nanowire thickness have been experimentally demonstrated at sub-80nm channel length. The effects of Forming Gas Anneal (FGA) on the performance of these devices have been systematically studied. The $30 \mathrm{~min} 400^{\circ} \mathrm{C}$ FGA $\left(4 \% \mathrm{H}_{2} / 96 \% \mathrm{~N}_{2}\right)$ is found to improve the quality of the $\mathrm{Al}_{2} \mathrm{O}_{3} / \mathrm{InGaAs}$ interface, resulting in a subthreshold slope reduction over $20 \mathrm{mV} / \mathrm{dec}$ (from $117 \mathrm{mV} / \mathrm{dec}$ in average to $93 \mathrm{mV} / \mathrm{dec}$ ). Moreover, the improvement of interface quality also has positive impact on the on-state device performance. A scaling metrics study has been carried out for FGA treated devices with channel lengths down to $20 \mathrm{~nm}$, indicating excellent gate 
electrostatic control. With the FGA passivation and the ultra-thin nanowire structure, InGaAs MOSFETs are promising for future logic applications.

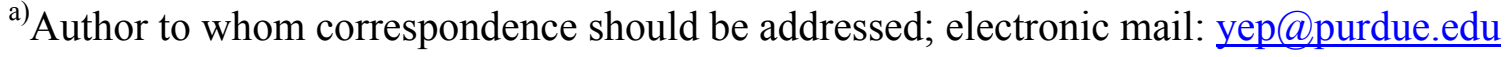
Recently, InGaAs has been considered as one of the promising channel materials for CMOS beyond the $10 \mathrm{~nm}$ technology node because of its large electron mobility. 3D InGaAs devices such as fin field-effect transistors and the gate-all-around (GAA) metaloxide-semiconductor field effect transistors have been shown to offer large drive current and excellent immunity to short channel effects (SCE) [1-6]. In particular, the GAA MOSFETs provide the best gate electrostatic control and therefore the ultimate channel length $\left(L_{c h}\right)$ scalability. It is known that better SCE control can be obtained by reducing the nanowire size, enabling further $L_{c h}$ scaling. InGaAs nanowires fabricated by top-down technology with sub-10nm wire dimension, either nanowire width $\left(W_{N W}\right)$ or thickness $\left(T_{N W}\right)$, have not been reported. On the other hand, the interface quality is one of the critical problems for III-V MOSFETs. Superior interface quality is required for optimizing both the on-state and off-state performance of MOSFETs. $\mathrm{Al}_{2} \mathrm{O}_{3}$ is commonly used as the gate insulator for InGaAs MOSFETs for the relatively low interface trap density $\left(D_{i t}\right)$. Various passivation methods have been developed and optimized on the $\mathrm{Al}_{2} \mathrm{O}_{3} / \mathrm{InGaAs}$ interface such as $\left(\mathrm{NH}_{4}\right)_{2} \mathrm{~S}$ passivation $[7,8]$, surface nitridation $[9,10]$ and phosphor passivation [11]. Forming Gas Anneal is another common post metallization treatment used to improve the interface quality of $\mathrm{Al}_{2} \mathrm{O}_{3} / \mathrm{InGaAs}$. Interface traps, oxide charges and border traps reduction after FGA have been reported by CV methods $[12,13]$. Recent study of effects of FGA on planar devices shows that on state performances such 
as drive current $\left(\mathrm{I}_{\mathrm{on}}\right)$ and transconductance $\left(\mathrm{g}_{\mathrm{m}}\right)$ are improved after FGA [14]. However, the impacts of FGA have not been studied in short channel devices with GAA structure. The compatibility between FGA and other passivation methods have not been studied either.

In this letter, 20-80nm $L_{c h}$ short channel $\operatorname{In}_{0.65} \mathrm{Ga}_{0.35}$ As GAA MOSFETs with $6 \mathrm{~nm}$ $T_{N W}$ and $30 \mathrm{~nm} W_{N W}$ have been fabricated with or without FGA treatment. FGA offers improvement in the on-state and off-state performance of the devices. The reduction of subthreshold slope (SS) and the increase of $g_{m}$ and $I_{o n}$ verify the improvement of the interface quality. The average interface trap density drops by $40 \%$ on average after FGA. Moreover, SS and drain induced barrier lowering (DIBL) do not increase when $L_{c h}$ scales from $80 \mathrm{~nm}$ down to $20 \mathrm{~nm}$, demonstrating the excellent scalability of InGaAs GAA MOSFET with sub-10nm nanowire dimension. It is also found that the $30 \mathrm{~min} 400^{\circ} \mathrm{C}$ FGA passivation is fully compatible with the $\left(\mathrm{NH}_{4}\right)_{2} \mathrm{~S}$ passivation. The interface trap density is significantly improved in devices with $\left(\mathrm{NH}_{4}\right)_{2} \mathrm{~S}$ passivation and FGA together than those with $\left(\mathrm{NH}_{4}\right)_{2} \mathrm{~S}$ passivation only.

Figure 1 (a) shows the schematic diagram of the InGaAs GAA MOSFET fabricated in this work and the cross sectional transmission electron microscope (TEM) image of an InGaAs nanowire with $6 \mathrm{~nm} T_{N W}$. The fabrication process flow of the devices is shown in Figure 1 (b). The top-down fabrication process is similar to that demonstrated in [4]. The starting material is a 2 inch semi-insulating InP substrate. $100 \mathrm{~nm}$ undoped $\mathrm{In}_{0.52} \mathrm{Al}_{0.48} \mathrm{As}$ etch stop layer, 80nm undoped InP layer, $10 \mathrm{~nm}$ undoped $\operatorname{In}_{0.65} \mathrm{Ga}_{0.35} \mathrm{As}$ 
channel layer and $2 \mathrm{~nm}$ undoped InP layer were sequentially grown by molecular beam epitaxy. Source/drain implantation was performed at an energy of $20 \mathrm{keV}$ and a dose of $10^{14} \mathrm{~cm}^{-2}$, followed by dopant activation at $600^{\circ} \mathrm{C}$ for 15 seconds in nitrogen ambient. After fabricating nanowire fins using $\mathrm{BCl}_{3} / \mathrm{Ar}$ reactive ion etching, $\mathrm{HCl}$ based release process was performed to create the free-standing InGaAs nanowires. Before the gate stack deposition, $10 \%\left(\mathrm{NH}_{4}\right)_{2} \mathrm{~S}$ passivation was performed. The gate dielectric is $5 \mathrm{~nm}$ atomic layer deposited (ALD) $\mathrm{Al}_{2} \mathrm{O}_{3}$ to study the effect of FGA on $\mathrm{Al}_{2} \mathrm{O}_{3} / \mathrm{InGaAs}$ interface while maintaining a low gate leakage current. Following ALD WN gate metallization process, the devices are divided into two groups. One is treated with $30 \mathrm{~min}$ $400^{\circ} \mathrm{C}$ FGA $\left(4 \% \mathrm{H}_{2} / 96 \% \mathrm{~N}_{2}\right)$ and the other serves as the control group. After gate etch process, source/drain contacts were formed with $\mathrm{Au} / \mathrm{Ge} / \mathrm{Ni}$ alloy. Each device has four nanowires fabricated in parallel. All patterns were defined by a Vistec UHR electron beam lithography system.

Figure 2 (a), (b) show the I-V characteristics comparison between two typical devices with $\mathrm{L}_{\mathrm{ch}}=20 \mathrm{~nm}, \mathrm{~W}_{\mathrm{NW}}=30 \mathrm{~nm}$ with and without $30 \mathrm{~min} 400^{\circ} \mathrm{C}$ FGA. Device with FGA shows an $89 \%$ increase in on-current $\left(\mathrm{I}_{\mathrm{on}}\right)$ at $\mathrm{V}_{\mathrm{ds}}=\mathrm{V}_{\mathrm{gs}}-\mathrm{V}_{\mathrm{T}}=0.8 \mathrm{~V}$ and the $\mathrm{SS}$ of device with FGA is $93 \mathrm{mV} / \mathrm{dec}$, which is $23 \mathrm{mV} / \mathrm{dec}$ smaller than that of device without FGA. Maximum $\mathrm{g}_{\mathrm{m}}$ of device with FGA is also found to be $59 \%$ larger than that of control device without FGA. After being normalized by the perimeter of the nanowire, the best $\mathrm{I}_{\mathrm{on}}$ and peak $\mathrm{g}_{\mathrm{m}}$ at $\mathrm{V}_{\mathrm{ds}}=\mathrm{V}_{\mathrm{gs}}-\mathrm{V}_{\mathrm{T}}=1 \mathrm{~V}$ is $505 \mu \mathrm{A} / \mu \mathrm{m}$ and $665 \mu \mathrm{S} / \mathrm{um}$, respectively. The saturation-currents of devices in this work are lower compared to InGaAs GAA 
MOSFETs with $30 \mathrm{~nm} \mathrm{~T}_{\mathrm{NW}}$ and the same $\mathrm{W}_{\mathrm{NW}}$ and $\mathrm{L}_{\mathrm{ch}}$ [4]. The reduction in drive current is attributed to the larger impact of surface roughness which decreases the channel mobility. Details of the transport properties of the ultra-thin nanowires are under investigation.

To study the effects of FGA, the average $\mathrm{SS}$, threshold voltage $\mathrm{V}_{\mathrm{T}}$, and $\mathrm{I}_{\text {on }}$ of InGaAs GAA MOSFETs with $\mathrm{L}_{\mathrm{ch}}$ between $20 \mathrm{~nm}$ and $80 \mathrm{~nm}$ have been extracted. Figure 3 (a) (b) and Figure 4 (a) show the statistical data of SS, $\mathrm{V}_{\mathrm{T}}$ and $\mathrm{I}_{\mathrm{on}}$ for devices with and without FGA. As shown in Figure 3 (a), devices with FGA has a much lower SS for all channel lengths compared to the control devices without FGA. The average of SS shows an obvious reduction from about $117 \mathrm{mV} / \mathrm{dec}$ to $93 \mathrm{mV} / \mathrm{dec}$. The improvement of the off state performance indicates that FGA can reduce the interface traps within the bandgap. The threshold voltage is found to increase with FGA treatment, as shown in Figure 3 (b). It is known that traps at the $\mathrm{Al}_{2} \mathrm{O}_{3} / \mathrm{InGaAs}$ interface are mostly donor type. The reduction of donor interface trap does not have a significant impact on the threshold voltage while the reduction of acceptor trap leads to negative $\mathrm{V}_{\mathrm{T}}$ shift [15]. Thus, the positive shift of $\mathrm{V}_{\mathrm{T}}$ in this study is attributed to the reduction of positive fixed charge density and the ion charge density in oxide layer. Figure 4 (a) shows the comparison of on-current. $\mathrm{I}_{\mathrm{on}}$ is found to increase by $14 \%$ on average with FGA, accompanied by $25 \% \mathrm{~g}_{\mathrm{m}}$ enhancement (not shown). One origin for the $\mathrm{I}_{\mathrm{on}}$ enhancement is the reduction of interface trap density near the conduction band edge. Another origin is that mobility is improved due to the reduction in Coulomb scattering as a result of oxide charge reduction. 
Interface trap density of the devices are extracted with the approximate formula $\mathrm{SS}=60\left(1+\left(\mathrm{qD}_{\mathrm{it}}+\mathrm{C}_{\mathrm{D}}\right) / \mathrm{C}_{\mathrm{ox}}\right) \mathrm{mV} / \mathrm{dec}[16]$, where $\mathrm{C}_{\mathrm{D}}$ is the depletion capacitance and $\mathrm{C}_{\mathrm{ox}}$ is the gate capacitance. The depletion capacitance can be neglected for its weak impact on SS. Devices in [4] shows the minimum SS of $63 \mathrm{mV} / \mathrm{dec}$, which indicates $\mathrm{C}_{\mathrm{D}}$ contribute to at most $3 \mathrm{mV} / \mathrm{dec}$ to $\mathrm{SS}$ in the InGaAs GAA MOSFET structure. As the device structure is similar as [4], $C_{D}$ is also negligible in this work. Thus, subthreshold swing can be written as $\mathrm{SS}=60\left(1+\mathrm{qD}_{\mathrm{it}} / \mathrm{C}_{\mathrm{ox}}\right) \mathrm{mV} / \mathrm{dec}$. It is estimated that the upper limit of mid-gap $\mathrm{D}_{\mathrm{it}}$ is reduced by $40 \%$ percent with FGA, indicating that FGA can improve the interface quality of the $\mathrm{Al}_{2} \mathrm{O}_{3} / \mathrm{InGaAs}$ interface.

Another interesting phenomenon found in this work is the standard deviation (STD) comparison for SS, $\mathrm{V}_{\mathrm{T}}$, and $\mathrm{I}_{\mathrm{on}}$. The SS STD and $\mathrm{V}_{\mathrm{T}} \mathrm{STD}$ of devices with FGA are smaller than the control devices without FGA, while the $\mathrm{I}_{\mathrm{on}}$ STD and $\mathrm{g}_{\mathrm{m}}$ STD of devices with FGA are larger than devices without FGA. The STD of SS and $V_{T}$ reduces with FGA treatment because of the improvement of the interface quality as shown earlier. However, the larger on-state STD seems unexpected and contradictory to the $\mathrm{D}_{\text {it }}$ reduction. The most possible reason is that the ohmic contact of the devices with FGA is worse than those without FGA, which can in turn increase on-state variation. To confirm this hypothesis, external resistance $\left(R_{\text {ext }}\right)$ is extracted by linear fitting $R_{\text {tot }}$ and $1 /\left(V_{g s}-V_{t}-\right.$ $\left.\mathrm{V}_{\mathrm{ds}} / 2\right)$ at small $\mathrm{V}_{\mathrm{ds}}$ [17]. As shown in Figure $4(\mathrm{~b})$, both average value of $\mathrm{R}_{\mathrm{ext}}$ and STD of $\mathrm{R}_{\text {ext }}$ of devices with FGA is much larger than devices without FGA. The larger $\mathrm{R}_{\text {ext }}$ of devices with FGA suggests that the intrinsic current improvement of devices with FGA is even larger than that shown in Figure 4 (a). Though the exact reason for the increased $R_{\text {ext }}$ 
after FGA has not been clearly understood, it is likely that the $\mathrm{Au} / \mathrm{Ge} / \mathrm{Ni}$ alloy based ohmic contact is sensitive to FGA treatment. More advanced source/drain contact technologies need to be explored to reduce the $\mathrm{R}_{\text {ext }}$ and improve on-state variation.

Furthermore, we investigate the scaling metrics of InGaAs GAA MOSFETs with $6 \mathrm{~nm} \mathrm{~T}_{\mathrm{NW}}$ and FGA. The $\mathrm{T}_{\mathrm{NW}}$ scaling of an InGaAs GAA MOSFET theoretically has the same effect as the $\mathrm{W}_{\mathrm{NW}}$ scaling in terms of the electrostatic control [4]. However, the scaling of $\mathrm{T}_{\mathrm{NW}}$ can reduce the surface area that has underwent dry etching process during the nanowire formation, leading to the reduced surface roughness. Figure 5 shows SS and DIBL versus $\mathrm{L}_{\mathrm{ch}}$ with $\mathrm{W}_{\mathrm{NW}}=30 \mathrm{~nm}$. No evidence of $\mathrm{L}_{\mathrm{ch}}$ dependence of $\mathrm{SS}$ and DIBL are observed in this work, as opposed to the InGaAs GAA MOSFETs with larger $\mathrm{T}_{\mathrm{NW}}$ [4]. The results show that the InGaAs GAA MOSFETs with extremely thin $\mathrm{T}_{\mathrm{NW}}$ offer better immunity to SCE and improved scalability which can be further improved by equivalent oxide thickness (EOT) scaling [4, 18, 19].

In conclusion, InGaAs GAA MOSFETs with $6 \mathrm{~nm} \mathrm{~T}_{\mathrm{NW}}$ have been fabricated. The effects of FGA on the performance of the devices are systematically studied. It is found that the $30 \mathrm{~min} 400^{\circ} \mathrm{C}$ Forming Gas Anneal results in a improved $\mathrm{Al}_{2} \mathrm{O}_{3} / \mathrm{InGaAs}$ interface and is also fully compatible with the $\left(\mathrm{NH}_{4}\right)_{2} \mathrm{~S}$ passivation. A scaling metrics study of the InGaAs GAA MOSFETs has also been carried out. The extremely thin nanowire structure has been shown to improve SCE immunity and it is very promising for future logic applications. 
The authors would like to thank D. A. Antoniadis, J. A. del Alamo, and M. S. Lundstrom for valuable discussions. This work is supported by SRC FCRP MSD Center and AFOSR, monitored by Prof. James C. M. Hwang. 


\section{References}

${ }^{1}$ J. J. Gu, Y. Q. Liu, Y. Q. Wu, R. Colby, R. G. Gordon, and P. D. Ye, in 2011 IEEE International Electron Devices Meeting (IEDM), 2011, 769.

${ }^{2}$ M. Radosavljevic, G. Dewey, D. Basu, J. Boardman, B. Chu-Kung, JM Fastenau, S. Kabehie, J. Kavalieros, V. Le, and WK Liu, in 2011 IEEE International Electron Devices Meeting (IEDM), 2011, 765.

${ }^{3}$ H.C. Chin, X. Gong, L. Wang, H. K. Lee, L. Shi, and Y. C. Yeo, IEEE Electron Device Lett. 32, 146 (2011).

${ }^{4}$ J. J. Gu, X. W. Wang, H. Wu, J. Shao, A. T. Neal, M. J. Manfra, R. G. Gordon, and P. D. Ye, in 2012 IEEE International Electron Devices Meeting (IEDM), 2012,633.

${ }^{5}$ F. Xue, A. Jiang, Y.-T. Chen, Y. Wang, F. Zhou, Y.-F. Chang and J. Lee, in 2012 IEEE International Electron Devices Meeting (IEDM), 2012, 629.

${ }^{6}$ Y. Q. Wu, R. S. Wang, T. Shen, J. J. Gu, and P. D. Ye, in 2009 IEEE International Electron Devices Meeting (IEDM), 2009, 331.

${ }^{7}$ É. O’Connor, B. Brennan, V. Djara, K. Cherkaoui, S. Monaghan, S. B. Newcomb, R. Contreras, M. Milojevic, G. Hughes, and M. E. Pemble, Journal of Applied Physics 109, $024101(2011)$. 
${ }^{8}$ J. J. Gu, A. T. Neal, and P. D. Ye, Applied Physics Letters 99, 152113 (2011).

${ }^{9}$ F. Capasso and G. F. Williams, Journal of The Electrochemical Society 129 (4), 821 (1982).

10 T. Hoshii, S. Lee, R. Suzuki, N. Taoka, M. Yokoyama, H. Yamada, M. Hata, T. Yasuda, M. Takenaka, and S. Takagi, Journal of Applied Physics 112, 073702 (2012).

${ }^{11}$ J. Lin, S. Lee, H. J. Oh, W. Yang, G. Q. Lo, D. L. Kwong, and D. Z. Chi, in 2008 IEEE International Electron Devices Meeting (IEDM), 2008, 401.

12 B. Shin, J. R. Weber, R. D. Long, P. K. Hurley, C. G. Van de Walle, and P. C. McIntyre, Applied Physics Letters 96, 152908 (2010).

${ }^{13}$ E. J. Kim, L. Wang, P. M. Asbeck, K. C. Saraswat, and P. C. McIntyre, Applied Physics Letters 96, 012906 (2010).

${ }^{14}$ V. Djara, K. Cherkaoui, M. Schmidt, S. Monaghan, E. O'Connor, I. M. Povey, D. O'Connell, M. E. Pemble, and P. K. Hurley, IEEE Transactions on Electron Devices 59, 1084 (2012).

${ }^{15}$ D. Varghese, Y. Xuan, Y. Q. Wu, T. Shen, P. D. Ye, and M. A. Alam, in 2008 IEEE International Electron Devices Meeting (IEDM), 2008, 379. 
${ }^{16}$ S.M. Sze and K.K. Ng, Physics of semiconductor devices. (Wiley-interscience, 2006).

${ }^{17}$ P. Hashemi, L. Gomez, and J. L. Hoyt, IEEE Electron Device Letters 30, 401 (2009).

${ }^{18}$ J. Lin, D. A. Antoniadis and J. A. del Alamo, in 2012 IEEE International Electron Devices Meeting (IEDM), 2012, 757.

${ }^{19}$ D.-H. Kim, P. Hundal, A. Papavasiliou, P. Chen, C. King, J. Paniagua, M. Urteaga, B. Brar, Y. G. Kim, J.-M. Kuo, J. Li, P. Pinsukanjana and Y. C. Kao, in 2012 IEEE International Electron Devices Meeting (IEDM), 2012, 761. 


\section{Figure Captions}

Figure 1 (a) Cross sectional TEM image and schematic diagram of an InGaAs GAA MOSFET with $\mathrm{T}_{\mathrm{NW}}=6 \mathrm{~nm}$. (b) Fabrication process flow of the InGaAs GAA MOSFETs.

Figure 2 (a) Output and (b) Transfer characteristics of two typical InGaAs GAA MOSFETs with $\mathrm{L}_{\mathrm{ch}}=20 \mathrm{~nm}, \mathrm{~W}_{\mathrm{NW}}=30 \mathrm{~nm}$ and $\mathrm{T}_{\mathrm{NW}}=6 \mathrm{~nm}$ with and without FGA treatment. Due to the significant reverse junction leakage current, $\mathrm{I}_{\mathrm{S}}$ is presented instead of $\mathrm{I}_{\mathrm{D}}$.

Figure 3 (a) SS and (b) $V_{T}$ of these devices with $\mathrm{W}_{\mathrm{NW}}=30 \mathrm{~nm}$ and $\mathrm{T}_{\mathrm{NW}}=6 \mathrm{~nm}$ versus $\mathrm{L}_{\text {ch }}$. With FGA and their control devices are in comparison. Each data point represents 5-10 measured devices. $\mathrm{V}_{\mathrm{t}}$ is extracted from linear extrapolation at $\mathrm{V}_{\mathrm{ds}}=50 \mathrm{mV}$.

Figure 4 (a) $\mathrm{I}_{\mathrm{on}}$ and (b) $\mathrm{R}_{\text {ext }}$ versus $\mathrm{L}_{\mathrm{ch}}$ in comparison between FGA devices and their control ones.

Figure $5 \mathrm{SS}$ and DIBL versus $\mathrm{L}_{\mathrm{ch}}$ of FGA treated InGaAs GAA MOSFETs with $\mathrm{W}_{\mathrm{NW}}=$ $30 \mathrm{~nm}$ and $\mathrm{T}_{\mathrm{NW}}=6 \mathrm{~nm}$. 


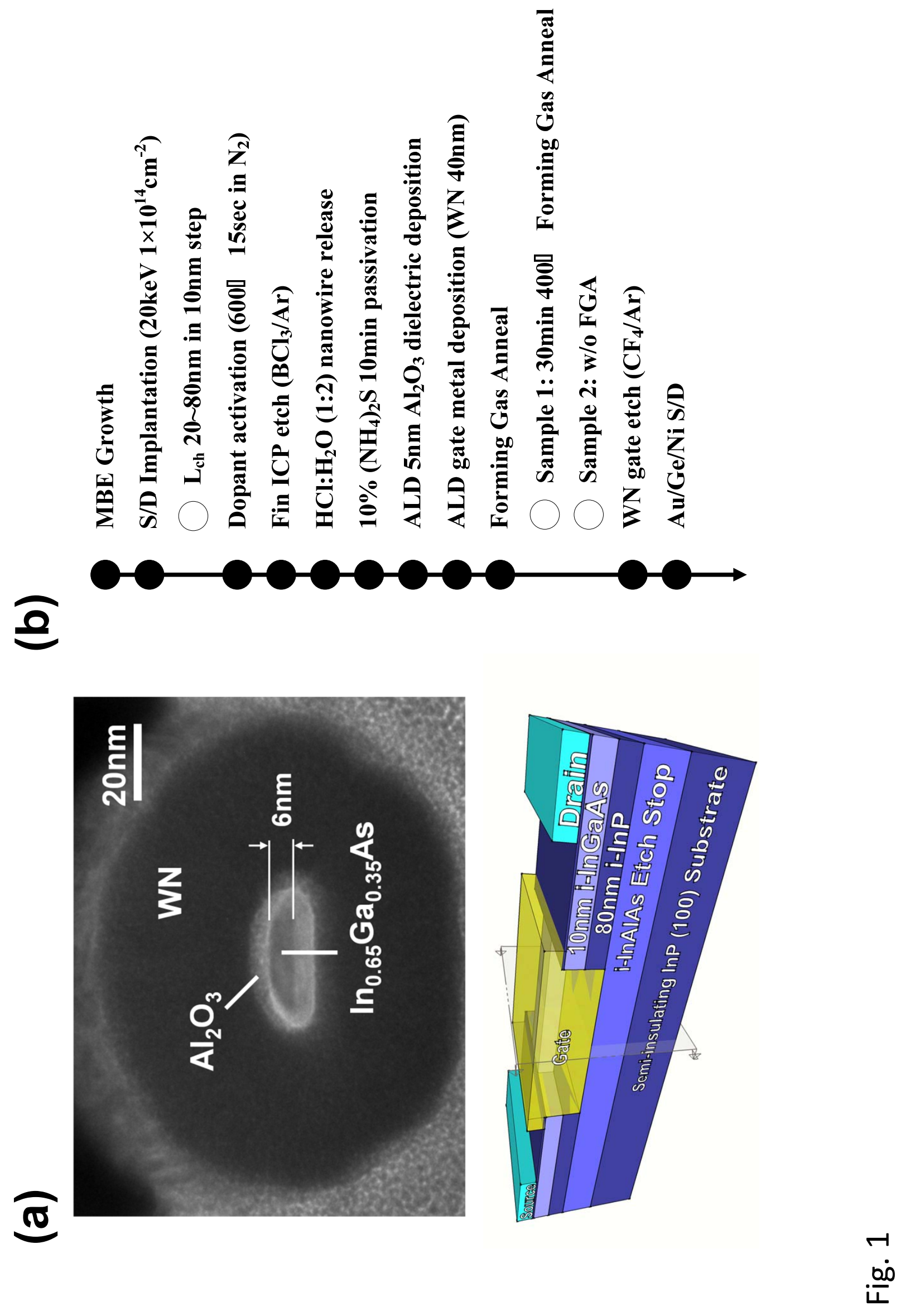



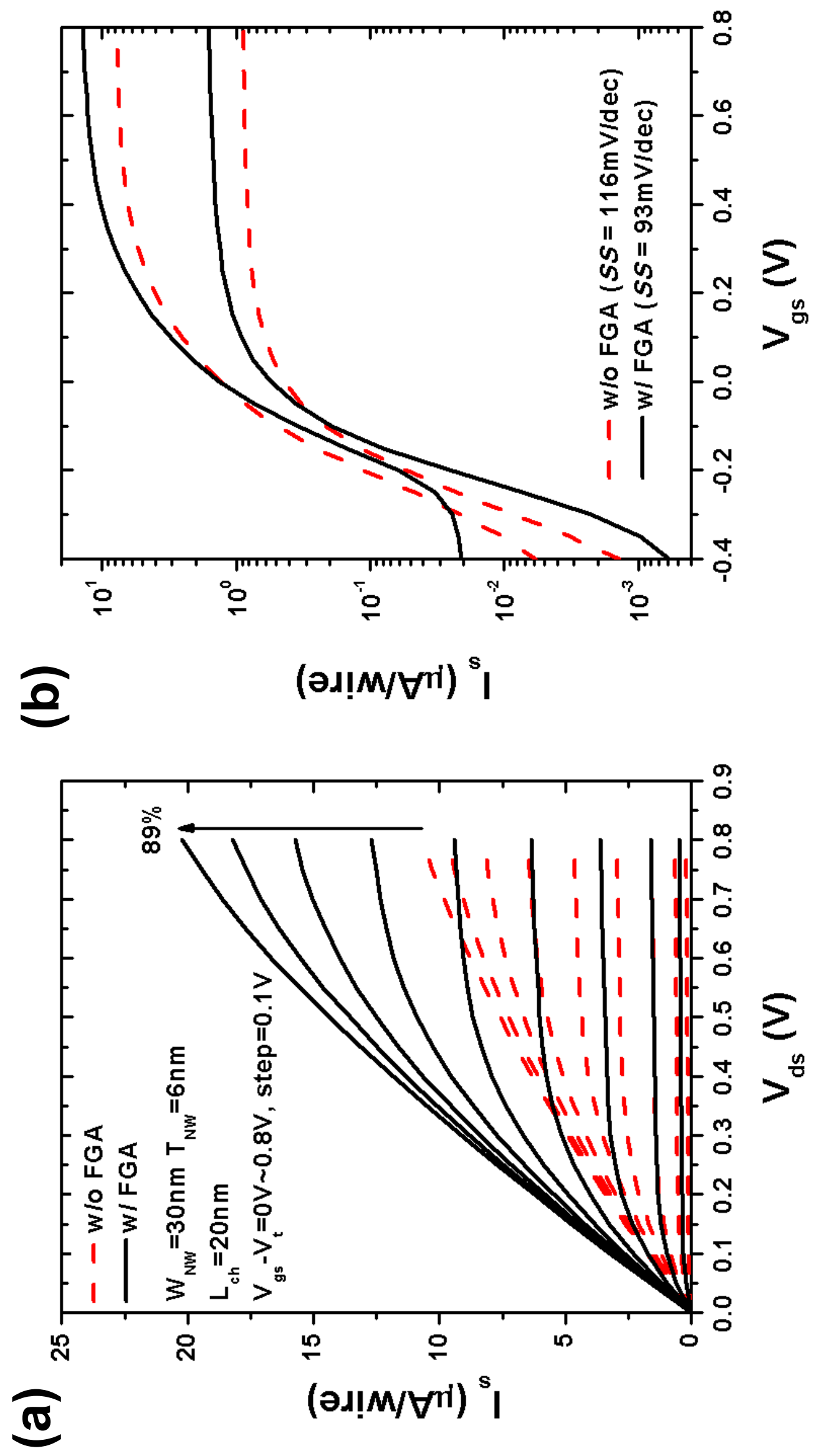

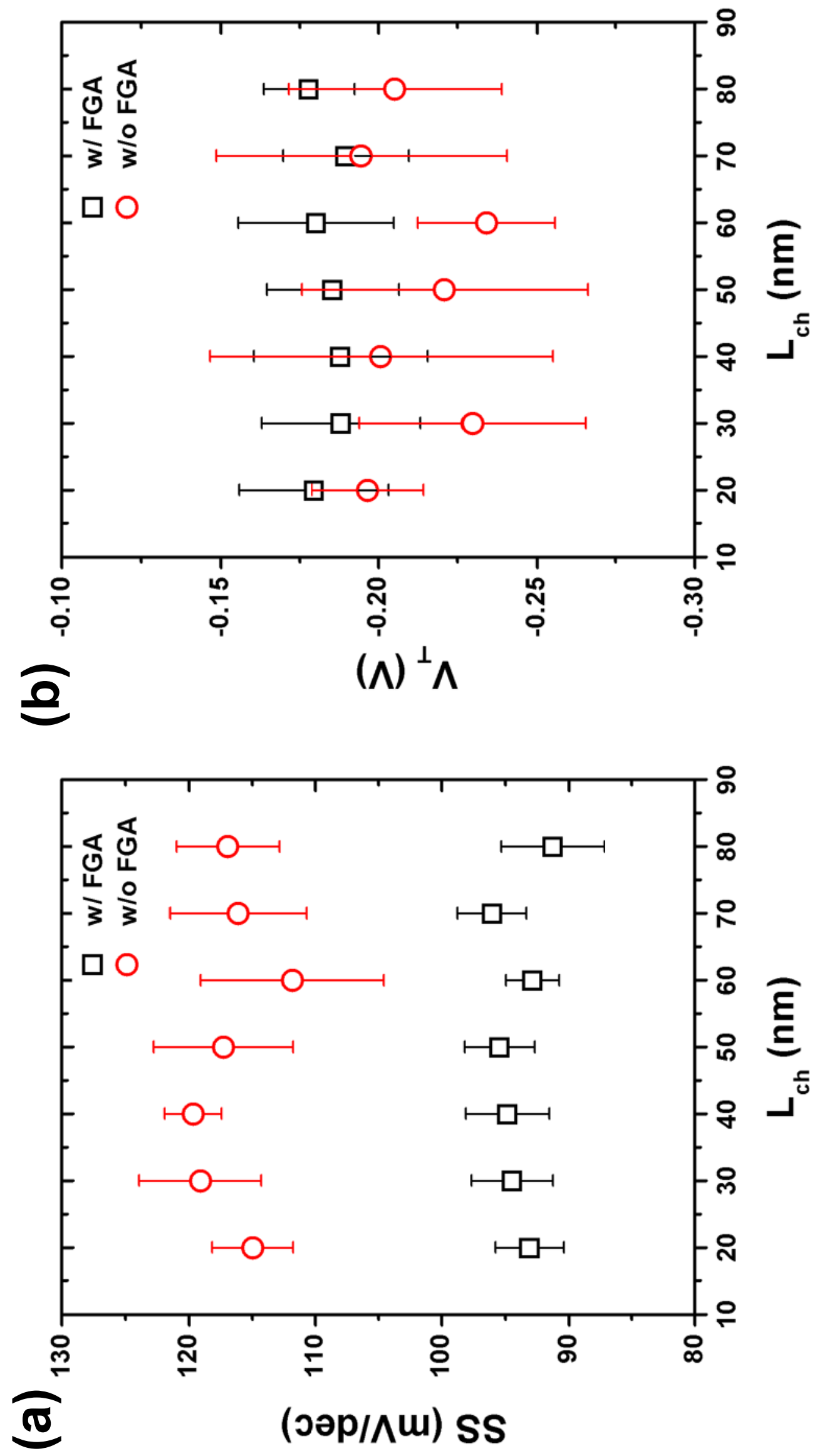

$m$
$\dot{i}$ 


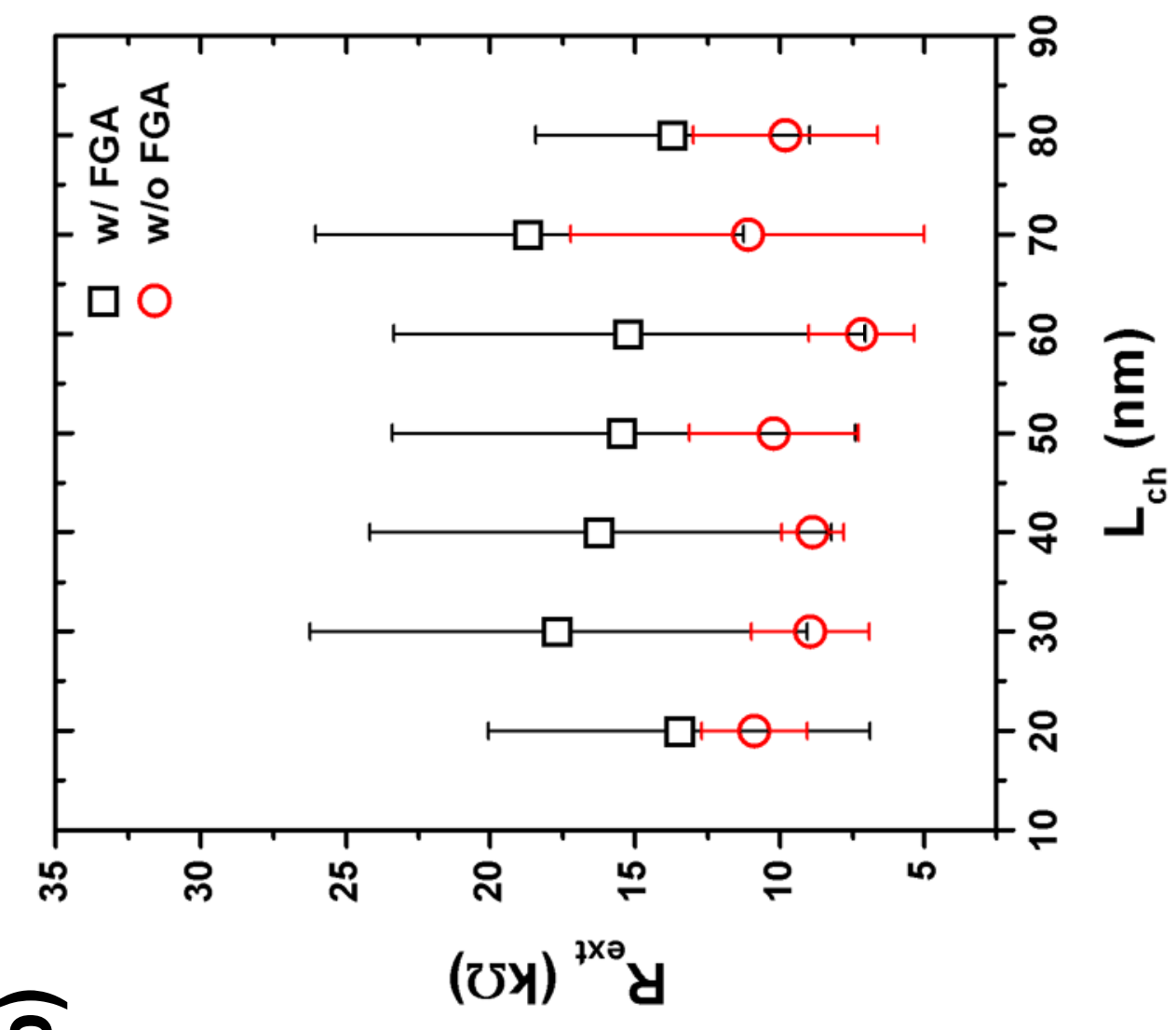

으

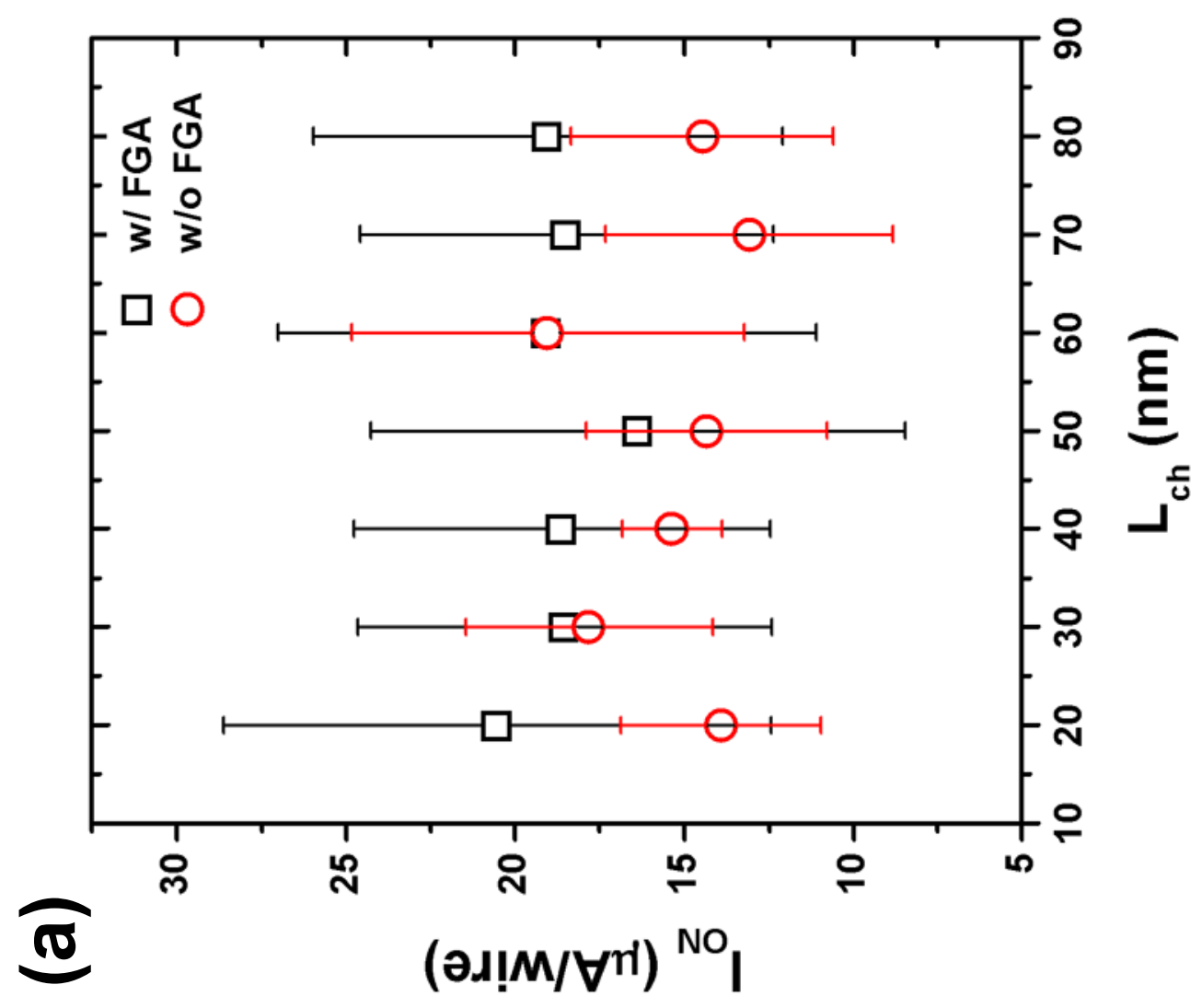

$\nabla$
i் 


\section{(N/AU) 7gום}

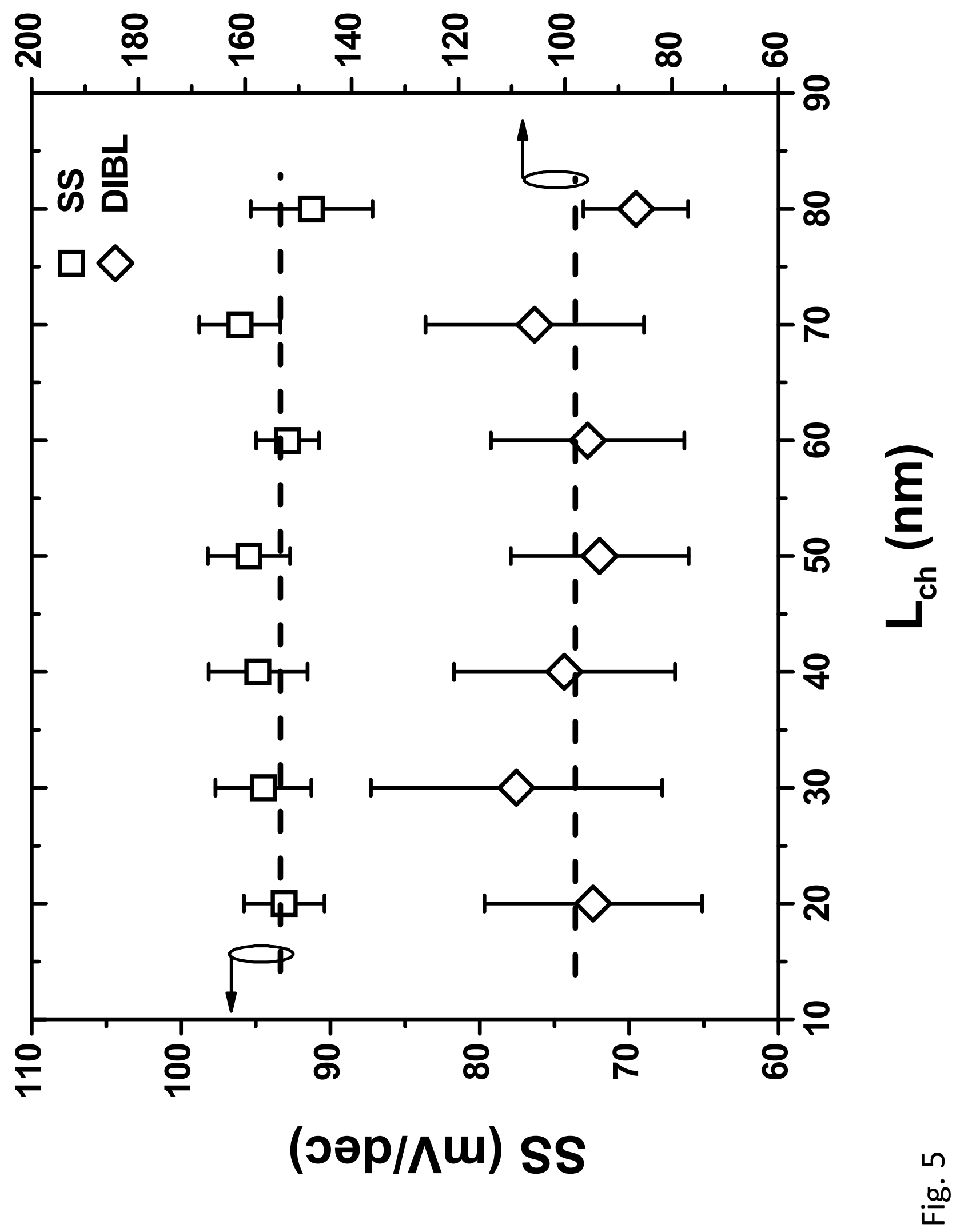

